\title{
A SUSTENTABILIDADE DE UMA PLATAFORMA COLABORATIVA E INTERATIVA DE MEMÓRIA: o estudo de caso da Rede de Histórias e do Espaço Memória do Banco de Desenvolvimento de Minas Gerais ${ }^{1}$
}

\author{
Cláudio Santos Rodrigues \\ UEMG - Universidade de Estado de Minas Gerais \\ claudio@voltz.com.br \\ Sérgio Antônio Silva \\ UEMG - Universidade de Estado de Minas Gerais \\ sergio.antonio74@hotmail.com
}

\begin{abstract}
Resumo: Para comemorar os 50 anos do Banco de Desenvolvimento de Minas Gerais (BDMG), foi desenvolvida uma Rede de Histórias como ferramenta para a troca e sistematização das informações. $O$ design de informação teve papel fundamental para a construção dessa rede digital e para o processo de resgate e construção da memória coletiva do desenvolvimento de Minas Gerais. A construção dessa memória partiu da criação de uma linha do tempo como fio condutor, e a continuidade do processo aconteceu através de diferentes formas de acesso e troca de informações. Foi abordada a memória para além da recuperação de informações e dados e, sim, estabelecendo um processo de rescontituição do passado em diálogo permanente com o presente. Pretende-se, então, apontar como essa rede colaborativa, desenvolvida entre abril e novembro de 2012, pode se manter ativa para o resgate e construção de memória coletiva de forma permanente, com as interações necessárias para sua sustentabilidade.
\end{abstract}

Palavras-chave: Design da informação, Memória coletiva, Colaboração, Redes digitais sustentáveis.

1 Artigo desenvolvido inicialmente na disciplina Design e Sustentabilidade, sob orientação dos professores Lia Krucken e Eduardo Romeiro, no Programa de Pós Graduação em Design da Universidade do Estado de Minas Gerais, em 2014. 


\begin{abstract}
To celebrate the $50^{\text {th }}$ anniversary of the Banco de Desenvolvimento de Minas Gerais (Development Bank of Minas Gerais), a "Network of Stories" has been developed as a tool for exchange and systematization of information. Information design has played a key role in building that digital network and in the process of recovery and construction of the collective memory of the development of Minas Gerais. The construction of that memory came from the creation of a timeline as a guide, and the continuity of the process happened through different ways of accessing and exchanging information. Memory was addressed beyond the retrieval of information and data, through the establishment of a process of reconstitution of the past in permanent dialogue with the present. Thus, the aim is to point out how this collaborative network, developed between April and November 2012, can remain active for the continuous rescue and construction of collective memory, with the necessary interactions to its sustainability.
\end{abstract}

Keywords: Information design, Collective memory, Collaboration, Sustainable digital networks.

\title{
1. INTRODUÇÃO
}

Com o aumento das cidades, desde a industrialização, fez-se necessária, a partir de uma nova ordenação do espaço urbano, a organização das informações de forma clara e concisa. Cardoso (2011) entende o surgimento das redes visuais de comunicação (por meio da sinalização) e das redes "invisíveis" de telecomunicação (inicialmente, o telégrafo elétrico) como necessárias ao bom funcionamento das redes existentes e para acompanhar as necessidades de um mundo em crescente expansão. Para esse autor, o design sempre esteve associado a qualquer rede existente.

Entre meados do séc. XIX e meados do séc. XX, a maior parte das grandes cidades do mundo passou por uma transformação colossal que consistiu na implantação ou reforma de série de redes de utilidades, como água, esgoto, gás e telefonia, além de uma ampliação das redes de transporte urbano e interurbano - rodovias, ferrovias, portos e aeroportos. [...] A história das grandes cidades, ao 
longo dos dois últimos séculos de modernidade, é a história de consolidação destas redes. No mundo industrial tudo é interligado. À medida que elas vão sendo integradas surge uma grande rede abarcando todas as outras - a de informação. (CARDOSO, 2011, p. 181-187).

Em paralelo à rede visual e à invisível, surgiu uma terceira rede, a da comunicação visual impressa: livros, revistas, jornais, mapas e outros artefatos móveis para a veiculação de texto e imagem. Posteriormente, podemos considerar que a internet criou uma nova rede, estabelecendo, a cada dia, uma nova forma de nos relacionarmos com as informações.

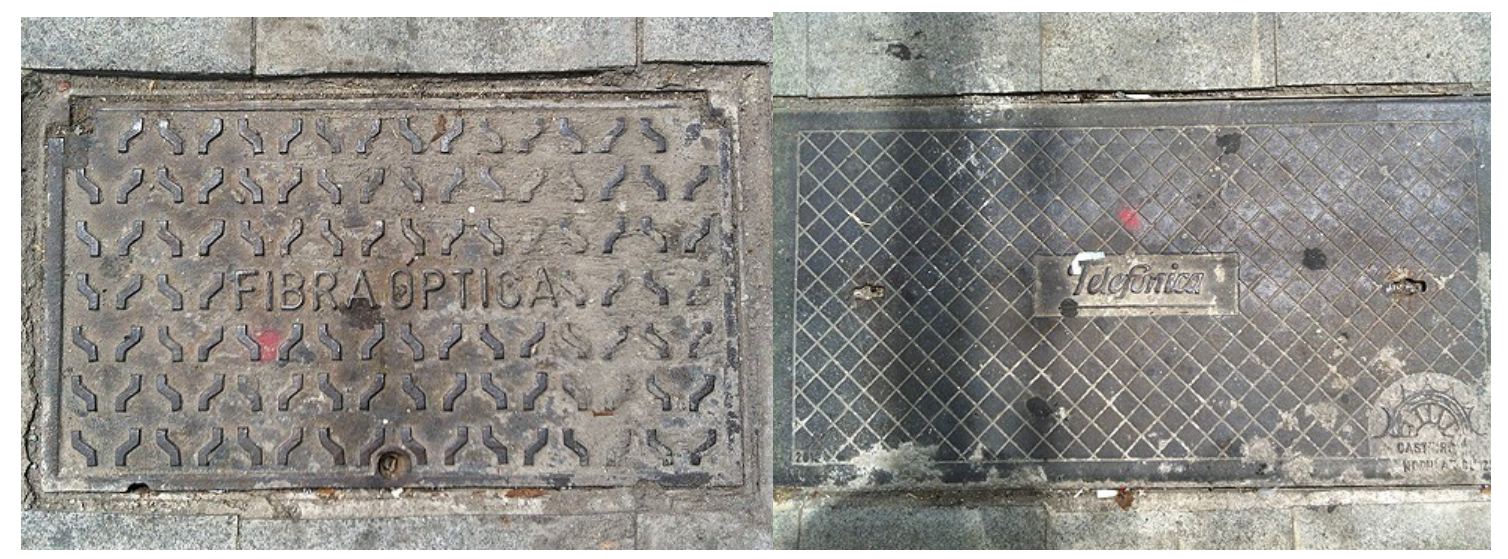

Figura 1 - Tampas de bueiro do largo da Batata, em São Paulo, 2013.

Fonte: Elaborado pelos autores, com base na pesquisa realizada.

A internet é, evidentemente, um meio e uma tecnologia para registro e processamento de informações, mas constitui igualmente um suporte para o design que permite integrar as informações das demais redes citadas: a visual, a invisível e a da comunicação visual. As redes citadas são registros de transformações que afetam a sociedade e isso inclui transformações culturais. O compartilhamento de coisas e informações sempre dependeu de uma rede. A partir do surgimento da Web 2.0, em que cada usuário pode criar seu próprio conteúdo, a forma de se relacionar com a internet mudou. É partir desse ponto que será estabelecida relação entre memória, rede e sustentabilidade.

\section{MEMÓRIA E REDE}

Nora (1993) apresenta-nos a diferença entre memória e história:

[...] longe de serem sinônimos, tomamos consciência que tudo opõe uma à outra. A memória é vida, sempre carregada por grupos vivos, 
aberta à dialética da lembrança e do esquecimento. A história é a construção sempre problemática e incompleta do que não existe mais. A memória é um fenômeno sempre atual, um elo vivido no eterno presente; a história, uma representação do passado.

A maioria das experiências que temos em nossas vidas se dá em função da memória. A capacidade de lembrar o que se já viveu ou aprendeu e relacionar isso com a situação presente é o mais importante mecanismo de constituição e preservação da identidade de cada um. Para os computadores, memória corresponde à capacidade de armazenamento e recuperação de dados. Deve ser abordada a memória para além da recuperação de informações e dados e sim estabelecer um processo de rescontituição do passado em diálogo permanente com o presente. Uma memória construída e mediada por metodologias e ações presenciais junto ao uso dos dispositivos digitais, aquilo que Flusser (2007) definiu como "conversação geral" ou "língua ampliada", o que abrange, além da linguagem verbal, a música, a plasticidade e a imagética.

Os novos meios, da forma como funcionam hoje, transformaram as imagens em verdadeiros modelos de comportamento e fazem dos homens meros objetos. Mas os meios podem funcionar de maneira diferente, a fim de transformar as imagens em portadoras e os homens em designers de significado. (FLUSSER, 2007, p.159).

Com isso, a necessidade de se armazenar e trocar essa abundância de novas imagens/mensagens fez com que todos se tornassem, potencialmente, publicadores de conteúdos. Com a evolução da tecnologia de transmissão de dados, essas trocas de dados e informações passaram a se tornar uma nova forma de estabelecer experiência para os usuários, através das redes digitais, que permitem a fluidez de todas as mídias. A palavra mídia passa a adquirir uma conotação de processo, produto e produção. Shirky (2010), em seu livro que trata da cultura da participação, traz a concepção de mídia enquanto tecido conjuntivo da sociedade. Dessa forma, a construção de memórias se dará levando em conta esses novos olhares sobe o significado de mídia.

Na sociedade em que vivemos, a cultura de rede se faz presente em todas as instâncias de nossas vidas. Segundo Cardoso (2011), boa parte da história do design passa pela configuração de redes que são crescentemente complexas. A formação de redes sociais é o desenvolvimento mais inclusivo, em termos culturais, do nosso tempo. Muitas organizações, tanto públicas quanto privadas, participam ou desejam participar de alguma rede, enxergando nela diferentes possibilidades para a resolução de seus problemas.

Em muitos casos, a constituição das redes é tratada como a solução por si só: as pessoas ou instituições se reúnem, manifestam o desejo de "trabalhar em rede" e pronto - tudo estará resolvido. Manter a rede ativa e sustentável, entretanto, constitui-se também como um enorme desafio a ser enfrentado. São vários os desafios que 
envolvem o registro, preservação e uso da memória no país. Estes devem ser cada vez mais assumidos não apenas pelos museus e outras instituições da área, mas também pelas comunidades, escolas, empresas e organizações sociais. (KRULIKOWISKY, 2007).

Uma rede é também um simulacro dos relacionamentos humanos, pois tem padrões de comportamento próprios das relações sociais. Nem sempre institucionalizada, uma rede nasce e se desenvolve naturalmente, sem que, para isso, os atores se preocupem em denominá-la como "rede", ou até mesmo em oficializá-la. E essa institucionalização não garante uma rede em pleno funcionamento: é fundamental que essa relação seja viva socialmente. Uma rede é viva quando o tecido social dela é vivo e alimentado constantemente pelas "trocas" que existem dentro dela. Quanto maior for o número de relacionamentos (e, portanto, de trocas, sejam elas de ideias ou de recursos), mais a rede estará viva.

O desafio do caso que apresentamos neste artigo passa a ser, então, o de criar o senso de pertencimento, participação e engajamento com a função de reunir, organizar e ressignificar todo o fluxo de informações gerado nas últimas cinco décadas do Banco de Desenvolvimento de Minas Gerais - BDMG -, além de proporcionar o encontro de pessoas que tiveram alguma relação com a instituição ao longo de sua trajetória e com a história do desenvolvimento em Minas Gerais.

A ideia é saber como manter e potencializar a participação, motivação, colaboração e generosidade contínuas. Para estabelecer a conexão entre o espaço físico construído para registrar essa história com o espaço virtual em construção permanente, pensa-se que o repasse das metodologias aplicadas junto ao design e as tecnologias da informação podem operar como campo de conhecimento fundamental para a manutenção desse novo território de possibilidades.

\subsection{A construção da Rede de Histórias e do Espaço Memória}

O BDMG comemorou, em 2012, seus 50 anos de existência. Uma data emblemática que mobilizou centenas de pessoas, entre funcionários, ex-funcionários, empresários, clientes, personalidades e executivos que fazem ou fizeram parte da trajetória dessa instituição. E, para alinhavar tudo isso, três empresas, trabalhando com variadas mídias, conceberam e desenvolveram o projeto BDMG Memória Viva, com o objetivo de retratar a dimensão de tal acontecimento: a Vecci Arquitetura e Design, a Voltz Design e a V Audiovisual.

Em uma primeira fase, foi desenvolvida uma plataforma virtual na internet, a Rede de Histórias, idealizada pela Voltz Design. Um site colaborativo com a função de reunir e organizar todo o fluxo de informações gerado nas últimas cinco décadas do BDMG, além de proporcionar o encontro de pessoas que tiveram alguma relação com a instituição ao longo de sua trajetória. Iniciado em abril de 2012, durante seis meses o site foi constantemente alimentado com os conteúdos enviados por seus participantes e pela equipe de conteúdo. 

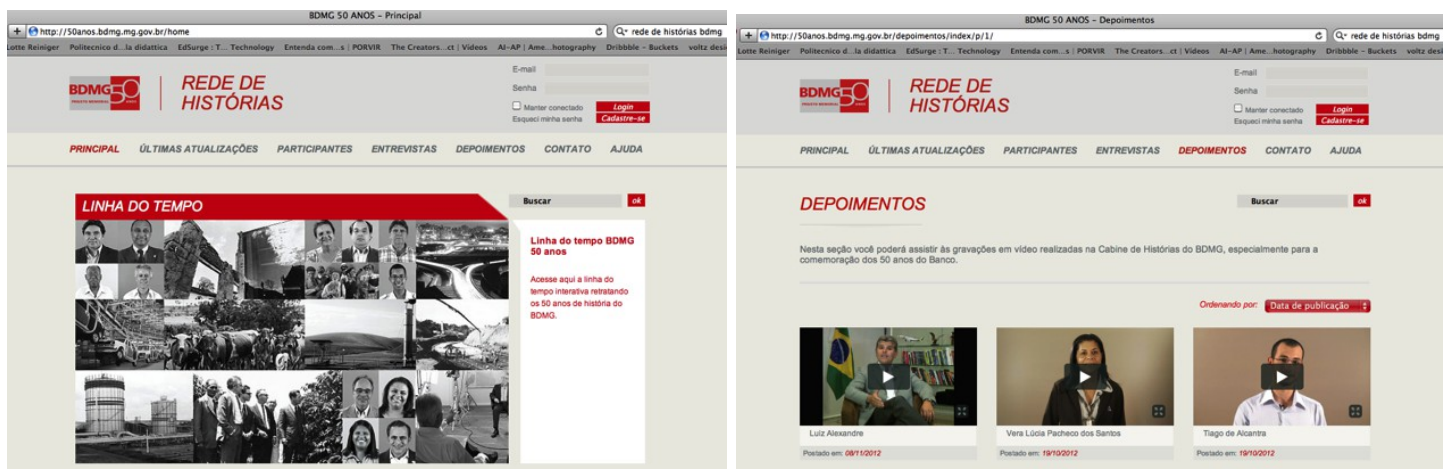

Figura 2 - Telas da Rede de Histórias (50anos.bdmg.mg.gov.br).

Fonte: Elaborado pelos autores, com base na pesquisa realizada.

Nesse primeiro momento da pesquisa, diversas mídias foram transpostas do acervo do BDMG para a plataforma on line. A partir disso, muitos usuários começaram a interagir com as postagens e a incrementar o conteúdo ou publicar comentários, fotos e vídeos. Realizamos um levantamento de dados nos arquivos do Banco organizando as informações, qualificando-as em função dos processos de significação dos dias atuais. Para a etapa posterior da pesquisa, buscamos os projetos mais relevantes desenvolvidos com o apoio do BDMG, que ainda hoje fazem parte da vida social dos mineiros, mais os fatos históricos. Recuperamos registros de grandes momentos vivenciados e proporcionados pelo BDMG, incluindo projetos relevantes para as diferentes regiões de Minas Gerais, o Estado como um todo e o País.

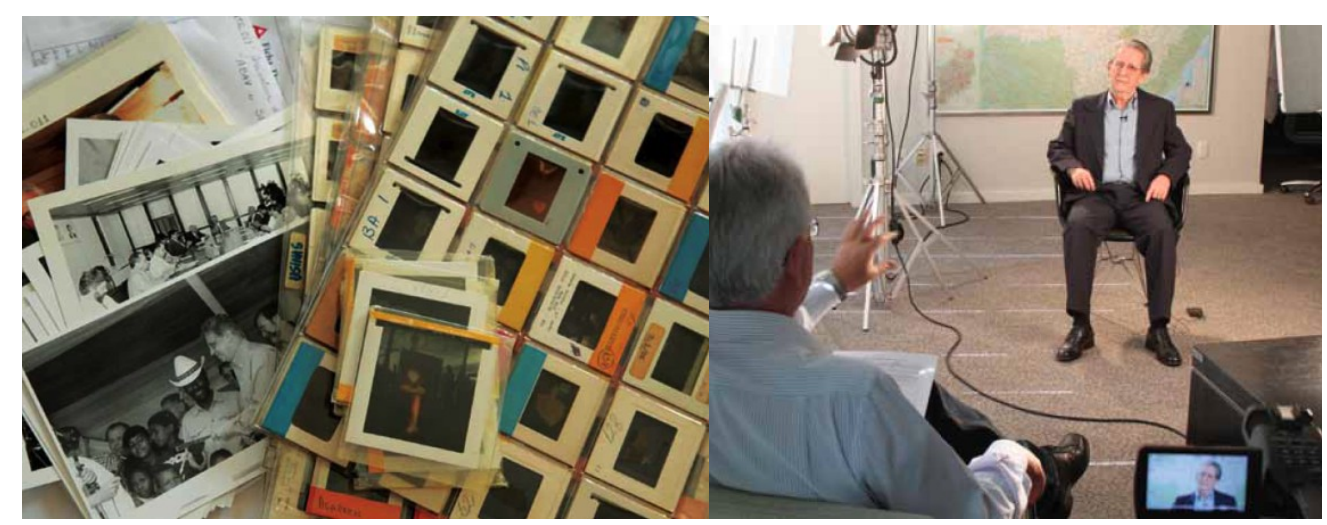

Figura 3 - Material de pesquisa e gravação de entrevistas.

Fonte: Elaborado pelos autores, com base na pesquisa realizada.

Ao monitorar a rede, surgiu a necessidade de gerar ações presenciais de ativação, visando aumentar ainda mais essa participação e torná-la mais dinâmica. Entre essas estão a cabine de depoimentos e as entrevistas realizadas pela $\mathrm{V}$ Audiovisual, tendo sido publicados aproximadamente duzentos trechos de vídeos gravados e editados durante todo o processo. Uma cabine instalada no saguão do BDMG colheu depoimentos de diversos funcionários e ex-colaboradores, clientes e parceiros do Banco, que serviram de subsídio para a construção da Rede de Histórias. Foram aproximadamente cento e vinte depoimentos que revelaram a vivacidade da 
memória e da história do BDMG. Além dos depoimentos gravados na cabine, foram realizadas entrevistas com algumas pessoas marcantes do Banco. Além disso, foi desenvolvido um trabalho de pesquisa associado ao levantamento de dados e informações que resgatou depoimentos importantes gravados anteriormente em outros contextos.

O levantamento de informações serviu como principal subsídio para a construção da linha do tempo possibilitando rever a inserção de fatos relevantes e a produção de uma versão mais atual e completa da história do Banco. A linha do tempo interativa permite que os usuários contribuam com novas mídias e comentários.

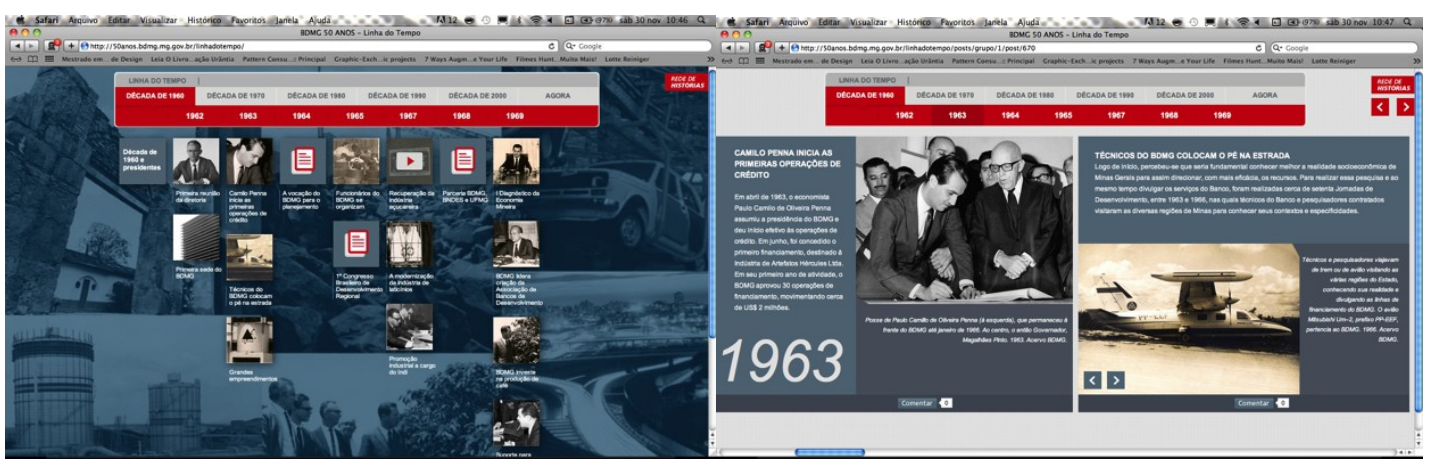

Figura 4: Telas da Linha do tempo interativa (50anos.bdmg.mg.gov.br/linhadotempo)

Fonte: Elaborado pelos autores, com base na pesquisa realizada.

Todo o site Rede de Histórias foi observado e monitorado por meio de métricas para acompanhamento de desempenho e interatividade. A análise dos gráficos e dos dados apontou para uma rápida apropriação da ferramenta eletrônica por parte do público final. Com essas informações geradas semanalmente, foi possível criar ações de ativação presencial e on line, além de ser um conteúdo fundamental para tomada de decisões e campanhas de comunicação.

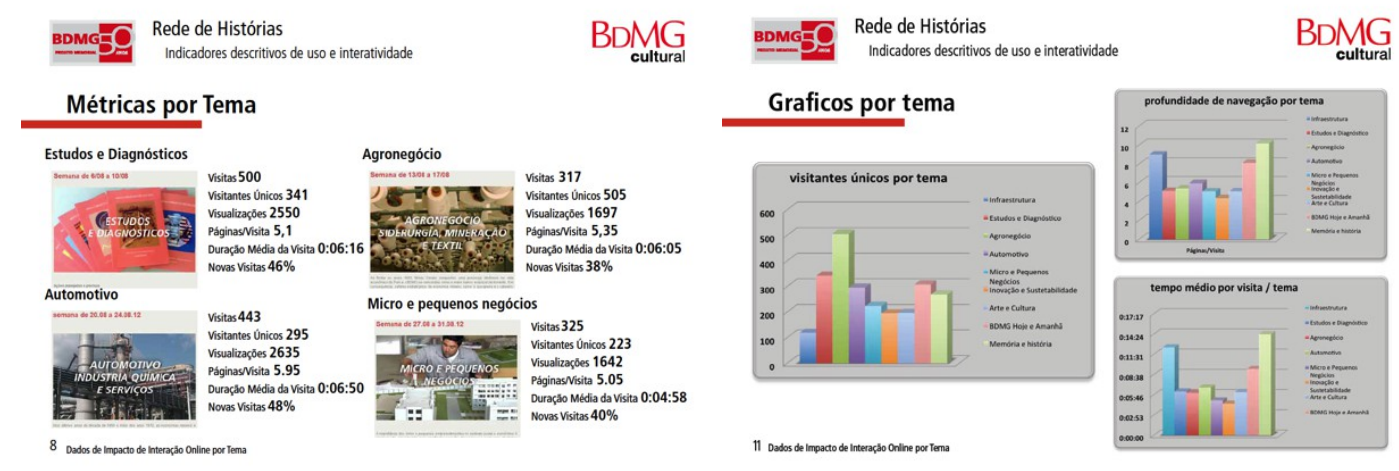

Figura 5 - Boletins de medição e análise de métricas.

Fonte: Elaborado pelos autores, com base na pesquisa realizada.

Simultaneamente à implantação da Rede de Histórias, a Vecci Arquitetura criou o projeto expográfico para o espaço permanente BDMG Memória Viva. Em uma 
segunda etapa, com a consolidação da linha do tempo e de novas implementações técnicas no hotsite, foi realizada a implantação do espaço BDMG Memória Viva, que integra diversas mídias. Não só o espaço virtual, mas também as instalações físicas e os conteúdos audiovisuais realizados permitem a pesquisa e acesso constante a todo o repertório sistematizado, expandindo a história do BDMG, do Estado e do País.

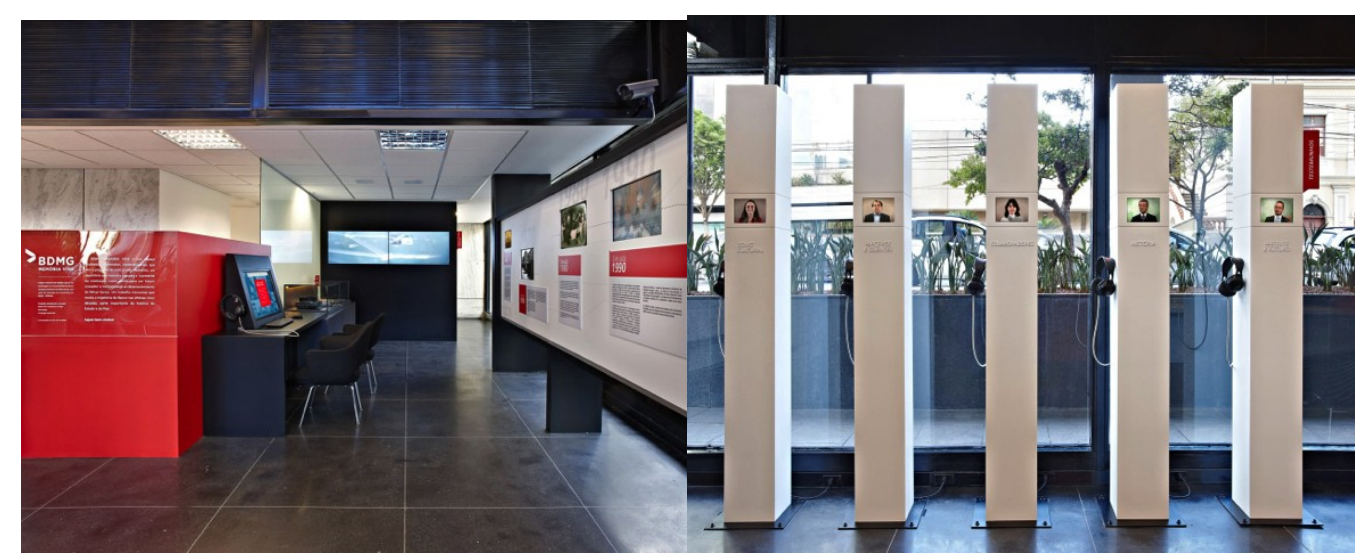

Figura 6 - Espaço BDMG Memória Viva, instalado e aberto ao público no hall de entrada da sede do banco em Belo Horizonte.

Fonte: Elaborado pelos autores, com base na pesquisa realizada.

O BDMG Memória Viva prevê, além das instalações audiovisuais, a continuidade da Rede de Histórias, conectada e aberta para participação pública. O resultado desse trabalho foi aberto ao público no dia 27 de setembro de 2012, constituindo-se em um espaço dedicado ao passado e ao presente do Banco, com vistas à projeção de seu futuro.

\subsection{Sustentabilidade e manutenção da rede}

Assim como as redes, o termo "sustentabilidade" também vem sendo cada dia mais empregado, sem que exista necessariamente uma percepção clara dos conceitos envolvidos. O conceito foi introduzido no início da década de 1980 por Lester Brown, fundador do Wordwatch Institute, que definiu como comunidade sustentável "aquela capaz de satisfazer às próprias necessidades sem reduzir as oportunidades das gerações futuras". (TRIGUEIRO, 2005, p.19).

Geralmente empregado quando nos referimos à captação de recursos financeiros, o conceito de sustentabilidade é transversal, sendo meio e fim ao mesmo tempo. No caso, pressupõe uma maneira de agir, para manter esse tecido vivo após o final do projeto em setembro de 2012. Com esse intuito, a ideia é trazer o conceito de sustentabilidade das redes digitais, levando-se em conta três aspectos.

O primeiro aspecto é a captação/injeção de recursos e o segundo é a replicação da metodologia utilizada no desenvolvimento da rede, para um grupo capacitado de funcionários da instituição. Já o terceiro diz respeito à capacidade da rede de se renovar constantemente através de novas interfaces e de ações contínuas de mobilização presencial e virtual. 
Em relação ao primeiro aspecto, ao longo do processo definiu-se que o projeto seria de responsabilidade do BDMG Cultural $^{2}$. O mesmo assumiu a gestão e manutenção da Rede de Histórias e do Espaço BDMG Memória Viva, alocando verba e recursos humanos.

Sob a égide do segundo aspecto, após a inauguração, passamos por um processo de negociação para o repasse da metodologia para o grupo responsável. Durante os meses de maio a setembro de 2013, mantivemos encontros presenciais para entrega do manual de utilização do sistema, assim como para dar consultoria na utilização de material de pesquisa existente a ser publicado com recorte editorial e suporte para apropriação da metodologia da nova equipe gestora do BDMG Memória Viva.

O que temos visto é uma apropriação da plataforma como espaço de geração de notícias conectadas aos conteúdos históricos disponibilizados. Porém, vê-se ainda pouca interação e participação de colaboradores externos.

Sob o aspecto da capacidade de renovação da rede, a fim de promover uma maior participação, o design passa a ser um dos elementos fundamentais para que o conteúdo atraia e faça com as pessoas colaborem com a rede. Uma nova onda de participação pode ser provocada por novos conteúdos que permitam a criação de aplicativos que se conectam com as redes socias de massa e com os dispositivos móveis para se expandir as formas de acesso.

Daí se faz necessário projetar novas interfaces, com nova arquitetura da informação, que implica o desenvolvimento de sistemas, assim como metodologias de análise de métricas, ações de comunicação, mobilização e engajamento que permitam as novas interações necessárias para a sustentabildiade dessa rede.

Manzini (2002) fragmenta o processo de projetar ao que ele chama de sistema de serviços colaborativos em quatro componentes críticos do design: fluidez de uso, replicação, acesso diversificado e melhoria do suporte a comunicações. O papel do designer é reduzir o limite de esforço, para que, independentemente da quantidade de força de vontade que um determinado usuário possa ter, o sistema consiga atingir seu objetivo.

A inovação contínua em design para melhorar os sistemas e integrar mais benefícios aos usuários é um campo de pesquisa que deve ser levado em conta. Conforme demonstram os princípios de Manzini (2002), os designers devem pensar cada vez mais sobre um sistema em que um produto ou serviço está sendo usado todas as interfaces físicas e culturais que se cruzam para criar o contexto do uso.

Levando-se em conta todos esses parâmetros, o design da informação permitirá que os resultados e processos de comunicação possam ser mais bem visualizados,

2 BDMG Cultural é uma entidade que apoia e estimula o desenvolvimento do cenário artístico e cultural no estado. Mantido pelo Banco de Desenvolvimento de Minas Gerais - BDMG, segue as diretrizes da instituição, priorizando a qualidade de vida dos mineiros com a inserção de uma consciência que prima pela educação cultural da sociedade. 
compreendidos e retrabalhados, através da participação, motivação, engajamento, colaboração e generosidade. A interatividade permitirá, ainda, diferentes pontos de vista na construção de uma memória coletiva, que só existe enquanto vivência e prática que se manifesta pelo cotidiano. Casaleno (2004) afirma que a riqueza da comunicação nesse ambiente está além do intercâmbio de informações, pois é preciso também considerar a densidade e qualidade desse intercâmbio.

\section{CONCLUSÃO}

Neste trabalho é exposta uma experiência de intervenção em uma instituição pública, procurando-se evidenciar a relação entre as pessoas que por ali estiveram e as que fazem parte da mesma, por meio de um ambiente de rede e com metodologia para resgate da memória, sob a perspectiva da sustentabilidade desse processo.

A experiência constou dos seguintes passos: criação de uma plataforma de rede colaborativa na internet, metodologia e ações presenciais de engajamento e participação, pesquisa de dados e cruzamento das informações e criação de espaço presencial para exibição e interação dos resultados. Pode-se constatar que se faz necessário criar novas interfaces e metodologias e que o design pode contribuir muito para esse processo.

Isso indica que a sustentabilidade da rede se dará por diversos artifícios e também pela identidade, o desejo, a motivação, o compromisso pessoal, a confiança e a transparência do processo. A Rede de Cooperação será tão forte e virtuosa quanto for a qualidade do engajamento das pessoas.

\section{REFERÊNCIAS}

ARTE E TECNOLOGIA. Recife: Fundação Joaquim Nabuco; Editora Massangana, 2010. BDMG CULTURAL. Disponível em: <http://www.bdmgcultural.mg.gov.br/index.php? link=2\&id=5> Acesso em: 30 nov. 2013.

BOOTSMAN, Rachel; ROOGERS, Roo. O que é meu é seu: como o consumo colaborativo vai mudar o nosso mundo. Trad. Rodrigo Sardenberg. Porto Alegre: Bookman, 2011.

CARDOSO, Rafael. Design para um mundo complexo. São Paulo: Cosac Naify, 2012.

FLUSSER, Vilém. O mundo codificado: por uma filosofia do design e da comunicação. Trad. Raquel Abi-Sâmara. São Paulo: Cosac Naify, 2007.

KRULIKOWSKI, Erick. Sustentabilidade de Redes. Encontro Cultura Popular e Educação. "Redes de contato: reinvenção solidária, pluralismo e diálogo entre culturas e civilizações" Montes Claros, 17 ago 2007.

LEÃO, Lúcia (Org.). Derivas Cartografias do Ciberespaço. São Paulo: Annablume; Senac, 2004. 
MANZINI, E.; VEZZOLI, C. O desenvolvimento de produtos sustentáveis. São Paulo: EDUSP, 2002.

MUSEU DA PESSOA. Disponível em:

<http://www.museudapessoa.net/_index.php/o_que_e/127-o-museu-> Acesso em: 30 nov. 2013.

NORA, Pierre. Entre memória e história: a problemática dos lugares. Projeto História. São Paulo, no 10, p. 7-28, dez. 1993.

SANTAELLA. Lucia. Cultura e artes do pós-humano: da cultura das mídias à cibercultura. São Paulo: Paulus, 2003.

SHIRKY, Clay. A cultura da participação: criatividade e generosidade no mundo conectado. Trad. Celina Portocarrero. Rio de Janeiro: Zahar, 2011.

TRIGUEIRO, André Capra. Meio ambiente no século XXI, 2005. 